\title{
Assessing the Synchronicity and Nature of Australian State Business Cycles
}

\author{
Aubrey Poon* \\ University of Strathclyde
}

\begin{abstract}
This paper assesses the synchronicity and nature of Australian State business cycles. To this end, I develop a time-varying parameter Panel Bayesian vector autoregression (BVAR) with a novel common stochastic volatility factor in the error structure, which is estimated in an efficient MCMC algorithm. The common stochastic volatility factor reveals that macroeconomic volatility was more pronounced during the Asian Financial Crisis as compared to the more recent Global Financial Crisis. Next, the Panel BVAR's common, state and variable specific indicators capture several interesting economic facts. In particular, the fluctuations of the common indicator closely follow the trend line of the Organisation for Economic Co-operation and Development (OECD) composite leading indicators for Australia, making it a good proxy for nationwide business cycle fluctuations. Furthermore, despite significant co-movements of Australian States and Territory business cycles during times of economic contractions, the State indicators suggest that the average degree of synchronisation across the Australian States and Territories cycles in the 2000s is only half of that in the 1990s. Given that aggregate macroeconomic activity is determined by cumulative activity of each of the States, the results suggests that the federal government should consider granting State governments greater autonomy in handling State specific cyclical fluctuations.

JEL classification: C11, E31, E32.

Keywords: Bayesian estimation, Australian States, Business Cycles, Time-varying parameter Panel BVAR, Common Stochastic Volatility Factor.
\end{abstract}

\footnotetext{
*Corresponding author. Email address: aubrey.poon@strath.ac.uk. The author would like to acknowledge financial support by The Economic Society of Australia via the 2015 Peter Kenyon Memorial Postgraduate Scholarship. The author would like to thank Jamie Cross, Chenghan Hou, Joshua Chan, Timothy Kam and Matteo Ciccarelli for helpful comments on the paper. Lastly, the author would like to thank the Editor, James Morley, for his comments which significantly improved the paper.
} 


\section{Introduction}

Following the recession of the early 1990s, the Australian economy has experienced two and a half decades of sustained economic growth. In fact, between 1990 and 2009, the average annual growth rate was 3.4 percent (Battellino, 2010), much greater than the 2.2 percent achieved by most Organisation for Economic Co-operation and Development (OECD) countries. The adoption of inflation targeting in 1993 and various microeconomic reforms, such as labour market and banking reforms, contributed to an environment where sustainable economic growth could be achieved. Heading into the 2000s, the Australian economy benefited greatly from the rapid economic development of many Asian economies. China overtook the US as Australia's top trading partner and became a larger importer of Australian commodities during this period. For instance, Au-Yeung et al. (2012) note that between 1999 and 2011, annual iron ore exports to China grew about 23 percent on average each year, growing from 26 million tonnes to 305 million tonnes. Due to this strong trading relationship with China and combined with a stable banking system, the Australian economy was largely unaffected by the Global Financial Crisis (GFC) (see Gerard and Kearns, 2011).

Although as a whole the Australian economy was growing strongly throughout this period, the onset of the mining boom in the mid-2000s saw the economic performances of Western Australia and Queensland far exceed their counterparts - a phenomenon that has been popularly characterised as a 'two speed economy' (Garton, 2008). With this in mind, the main objective of this paper is to assess the synchronicity of Australian State business cycles during this period of sustained growth ${ }^{1}$. In particular, I aim to determine whether States' cycles were more synchronised during the 1990s or the 2000s. I also further examine the nature of Australian State business cycles during the GFC period, when the Australian economy as a whole was largely unaffected.

The empirical literature on Australian State business cycles is scarce. In fact, the only

1Throughout the paper I use the term "States" to refer to all six Australian States:New South Wales (NSW), Victoria (VIC), Queensland (QLD), South Australia (SA), Western Australia (WA) and Tasmania (TAS), and the two territories: the Australian Capital Territory (ACT) and Northern Territory (NT). 
other study that attempts to examine the degree of co-movement among Australian State business cycles is Norman and Walker (2007). In their paper, Norman and Walker (2007) begin by conducting a correlation analysis of Gross State Product (GSP), to document statistically significant evidence of co-movement amongst the economically larger States of NSW, VIC, QLD and WA. This result is consistent with the findings of Dixon and Shepherd (2001) who conducted a related study examining co-movements in State unemployment, as opposed to economic output. Having provided statistically significant evidence of co-movement within the economically larger State business cycles, Norman and Walker (2007) then employ a multivariate unobserved components (UC) model through which they find that the main source of fluctuations in state specific economic activity is driven by a common shock. This finding then motivates their conclusion that common shocks are a more important driver of State level business cycle fluctuations than State specific shocks.

A major concern in utilizing a UC model to assess the synchronicity and nature of Australian State business cycles is that it fails to account for the dynamic interdependencies of the multi-state (or country) level data ${ }^{2}$. To account for this important feature of the data, I propose the use of a time-varying parameter Panel Bayesian vector-autoregression (BVAR) model. Originally put forth by Canova et al. (2007), the time-varying parameter Panel BVAR model has been employed in various studies which assess the similarities and co-movement of business cycles among different countries. For instance, Canova et al. (2007) and Canova and Ciccarelli (2012) employ this methodology to assess the similarities and convergence of business cycles of the G-7 and Mediterranean economies, especially more recently, Ciccarelli et al. (2016) employed the model to investigate the evolution and heterogeneity in macro-financial linkages and international spillover effects across developed economies.

Compared to a traditional BVAR model, the Panel BVAR has two distinct advantages when seeking to examine the synchronicity of business cycles. First, the Panel BVAR is designed for large scale dynamic models that display unit specific dynamics and cross coun-

${ }^{2}$ Dynamic interdependencies refers to the idea that lags of the endogenous variables within the States should enter into each of the other State's equations. 
try lagged inter-dependencies; as opposed to a traditional BVAR which suffers from the curse of dimensionality. Second, the parsimonious parameterisation proposed in Canova and Ciccarelli (2009) allows the researcher to consider time-varying coefficients through which indicators of common and country specific cycles are recursively constructed and dynamically span across country interdependencies.

One shortcoming of the standard Panel BVAR model when it comes to addressing our research question is that it assumes that the distribution of the macroeconomic shocks are constant over time.The aforementioned mining boom however, signifies that allowing for structural instabilities in shocks may be an important feature of Australian macroeconomic time series. To accommodate this feature of the data, I propose a simple extension of the time-varying parameter Panel BVAR by incorporating the common stochastic volatility factor into the error covariance structure. Originally proposed by Carriero et al. (2016), this common stochastic volatility factor structure significantly improves model fit and forecast accuracy of large BVARs compared to their constant volatility counterparts. ${ }^{3}$

In addition to this simple methodological extension, I also contribute towards the efficient estimation of the time-varying parameter Panel BVAR model both with and without the additional common stochastic volatility factor. More precisely, following Chan and Jeliazkov (2009) and Chan and Hsiao (2014), I implement precision based algorithms in the estimation of the model's time-varying parameters and the common stochastic volatility factor respectively. The main reason I adopt this precision sampler technique is due to its computation efficiency advantage over conventional Kalman filtering and smoothing techniques adopted in the aforementioned papers.

Taken together, this study can been viewed primarily as an extension of the study by Norman and Walker (2007) with important secondary econometric contributions in terms of the time-varying parameter Panel BVAR model. The results of the analysis reveal several key insights. Firstly, from a econometric perspective, I show that the inclusion of the common

${ }^{3}$ For related literature on the use of stochastic volatility in improving model fit and forecastability, I refer the reader to, for example: Clark (2014), Clark and Ravazzolo (2015) and Cross and Poon (2016) for out-of-sample point and density forecasting, or Chan and Eisenstat (2016) for in-sample analysis. 
stochastic volatility factor to the model significantly improves the in-sample goodness of fit. This result confirms our aforementioned hypothesis that stochastic volatility is an important feature when modelling the Australian economy. In addition to being statistically important, the common stochastic volatility factor reveals that the degree of volatility in the Australian economy was more pronounced during the Asian Financial Crisis rather than the recent GFC. Secondly, in addition to other interesting features, the common indicator from the time-varying Panel BVAR is able to capture the early 1990's recession along with the GFC. This modelling feature supports the hypothesis of strong common co-movement across each Australian State during times of economic contraction. Thirdly, I found that, on average, the common indicator is able to explain about 39 per cent of fluctuations across each of the State indicators and about 25, 8, 9 and 111 per cent of fluctuations in consumption, employment, retail turnover and investment indices respectively ${ }^{4}$ Lastly, I found the common indicator fluctuations closely follow the trend line of the OECD composite leading indicators (CLI) for Australia, especially during the 2000s. This suggests that the common indicator captures the majority of fluctuations in economic activity for our sample period.

Finally, in regards to Australian State business cycles, I found that the average degree of synchronisation across Australian States cycles has decreased to about half (from 10\% to $5 \%$ ), in terms of correlation from the 1990s to 2000s. I also found that the fall in consumption growth was the main factor in driving the negative effects of the GFC across the majority of the States. However, for the SA and NT economies, State-specific idiosyncratic factors were the dominant feature in driving this crisis. Turning to the period of 2013 to 2015, all four common variable type indices had minimal impact in the contribution of the downturn experienced within the WA, SA, VIC, ACT, and NT economies.

With these results in mind, our analysis has important implications for policymakers at both a state and federal level. Given that aggregate macroeconomic activity is determined by

\footnotetext{
${ }^{4}$ Note the reason the common indicator explains a extremely large share of fluctuation in investment is due to the fact that the sample variance of the investment indicator is smaller than the sample variance of the common indicator. To calculate how much the common indicator explains in investment fluctuations, I divide the sample variance of the common indicator by the sample variance of the investment indicator.
} 
cumulative activity of each of the States, the results suggest that federal governments should consider granting state governments greater autonomy in handling state specific cyclical fluctuations.

The rest of this paper is organised as follows. Section 2 explains the empirical approach by illustrating the estimation procedure for the time-varying parameter Panel BVAR model, the data and the priors for the model. Section 3 describes empirical results from the time-varying parameter Panel BVAR model, and Section 4 concludes and discusses the results.

\section{Econometric Approach}

\subsection{Panel BVAR}

The econometric model that I use in this paper is a time-varying parameter Panel BVAR from Canova et al. (2007). The model can be written as:

$$
\mathbf{y}_{i t}=\mathbf{c}_{i t}+\mathbf{A}_{1, i t} \mathbf{Y}_{t-1}+\ldots+\mathbf{A}_{p, i t} \mathbf{Y}_{t-p}+\mathbf{u}_{i t}
$$

where $t=1, \ldots T$ denotes time, $i=1, \ldots, N$ denotes the number of Australian States in the model, $\mathbf{A}_{p, i t}$ are $G \times N G$ time-varying matrices of the coefficients for each lag $j=1, \ldots p$, while $\mathbf{c}_{i t}$ and $\mathbf{u}_{i t}$ are $G \times 1$ vectors of intercepts and random disturbances respectively. The vector $\mathbf{y}_{i t}$ is $G \times 1$ of observed endogenous variables that consist of consumption growth, employment growth, retail turnover growth and investment growth for each State $i$ and $\mathbf{Y}_{t}=\left(\mathbf{y}_{1 t}^{\prime}, \ldots, \mathbf{y}_{N t}^{\prime}\right)^{\prime}$. Note that the endogenous variables for each Australian State depends on the lags of the endogenous variables for every Australian State. I refer to this feature as cross-unit lagged interdependencies.

The model exhibits three key features that are important in our study. First, the coefficients are allowed to be time-varying. Without time variation, it would be impossible 
to study the evolution of business cycle characteristics over time. Secondly, dynamic relationships are allowed to be State specific. Without this feature, heterogeneity bias may be present and economic conclusions can become easily distorted. Lastly, the cross-unit lagged inter-dependencies, which are captured by the coefficients matrix $\mathbf{A}_{p, i t}$ in the model, are likely to be important in explaining the dynamics of multi-region (Australian States) data. Canova et al. (2007) notes that these three factors are essential when one wants to study the similarities, propagation and time variations in the structure of business cycles across regions (in this case Australian States).

For estimation purposes the model in (1) can be re-written into standard linear regression matrix form:

$$
\mathbf{Y}_{t}=\mathbf{X}_{t} \boldsymbol{\beta}_{t}+\mathbf{u}_{t}
$$

where $\mathbf{X}_{t}=\mathbf{I}_{N G} \otimes\left(\mathbf{Y}_{t-1}^{\prime}, \ldots, \mathbf{Y}_{t-p}^{\prime}, 1\right)$ is a $N G \times N G k$ matrix (where $\left.k=N G p+1\right), \boldsymbol{\beta}_{\boldsymbol{t}}=$ $\operatorname{vec}\left(\left[\mathbf{A}_{t}, \mathbf{c}_{t}\right]^{\prime}\right), \mathbf{A}_{t}=\left[\mathbf{A}_{1 t}^{\prime}, \ldots, \mathbf{A}_{N t}^{\prime}\right]^{\prime}, \mathbf{A}_{i t}=\left[\mathbf{A}_{1, i t}, \ldots, \mathbf{A}_{p, i t}\right], \mathbf{c}_{t}=\left(\mathbf{c}_{1 t}^{\prime}, \ldots, \mathbf{c}_{N t}^{\prime}\right)^{\prime}$ and $\mathbf{u}_{t}=$ $\left(\mathbf{u}_{1 t}^{\prime}, \ldots, \mathbf{u}_{N t}^{\prime}\right)^{\prime}$. Note that $\boldsymbol{\beta}_{\boldsymbol{t}}$ is an $N G k \times 1$ vector that denotes the number of parameters in each time period. The sheer dimensionality of this vector makes classical estimation infeasible. To overcome this problem, Canova et al. (2007) propose that $\boldsymbol{\beta}_{\boldsymbol{t}}$ follows a linear structure:

$$
\boldsymbol{\beta}_{\boldsymbol{t}}=\Xi_{1} \theta_{1 t}+\Xi_{2} \theta_{2 t}+\Xi_{3} \theta_{3 t},
$$

where $\Xi_{1}, \Xi_{2}, \Xi_{3}$ are known matrices of dimensions $N G k \times 1, N G k \times N, N G k \times G$ respectively and $\theta_{1 t}, \theta_{2 t}, \theta_{3 t}$ are mutually orthogonal latent factors. Before defining these matrices and factors in more detail, note that the factorization transforms the over-parameterised panel BVAR into a parsimonious SUR model, where the regressors are averages of certain right- 
hand side VAR variables. Moreover, note that instead of estimating $N G k \times 1\left(\boldsymbol{\beta}_{\boldsymbol{t}}\right)$ coefficients, only $1+N+G\left(\boldsymbol{\theta}_{\boldsymbol{t}}\right)$ coefficients are estimated in the model in each period of time.

I now define each of the elements in (3). First, note that the deterministic matrices $\Xi_{i}$ 's are matrices of ones and zeros that, when combined with the latent factors and data, are designed to capture the common movements across the cross-sectional information of the data. Second, $\theta_{1 t}$ is a scalar that captures components in the coefficient vector that are common across all States' endogenous variables; $\theta_{2 t}$ is an $N \times 1$ vector that captures movements in the coefficient vector which are common within each individual States; and $\theta_{3 t}$ is a $G \times 1$ vector that captures movements in the coefficient vector which are specific to each endogenous variable across all States. To illustrate the mechanics of (3), I consider a simple example with only two States $N=2$, two endogenous variables $G=2$ and one lag $p=1:$

$$
\beta_{t}=\left[\begin{array}{c}
1 \\
1 \\
\vdots \\
1
\end{array}\right] \theta_{1 t}+\left[\begin{array}{cc}
\iota_{1} & 0 \\
\iota_{1} & 0 \\
0 & \iota_{2} \\
0 & \iota_{2}
\end{array}\right] \theta_{2 t}+\left[\begin{array}{cc}
\iota_{3} & 0 \\
0 & \iota_{4} \\
\iota_{3} & 0 \\
0 & \iota_{4}
\end{array}\right] \theta_{3 t}
$$

where $\iota_{1}=[1,1,0,0,0]^{\prime}, \iota_{2}=[0,0,1,1,0]^{\prime}, \iota_{3}=[1,0,1,0,0]^{\prime}$ and $\iota_{4}=[0,1,0,1,0]^{\prime}$. From this example, it is clear that $\Xi_{1}$ is interpreted to be drawing information from all the factors in the model, $\Xi_{2}$ is only capturing information from the factors specific to each State and lastly, $\Xi_{3}$ is only capturing information from the factors specific to each endogenous variable across all States. In sum, the imposed structure of $\Xi_{i}$ 's (in combination with $\mathbf{X}_{t}$ and $\boldsymbol{\theta}_{\boldsymbol{t}}$ ) allows us to recursively construct indicators or proxies of each Australian State business cycles, a common Australian business cycle and a variable specific common cycle across all the States, while taking in consideration the independencies between each States.

The final requirement of the specification is to define the laws of motion for the latent factors. To this end, let $\boldsymbol{\theta}_{\boldsymbol{t}}=\left(\theta_{1 t}, \theta_{2 t}, \theta_{3 t}\right)^{\prime}$. Following Canova et al. (2007) I assume that $\boldsymbol{\theta}_{\boldsymbol{t}}$ evolves over time according to a random walk: 


$$
\boldsymbol{\theta}_{\boldsymbol{t}}=\boldsymbol{\theta}_{\boldsymbol{t}-\mathbf{1}}+\eta_{t}, \quad \eta_{t} \sim N(0, \Omega)
$$

where $\Omega=\operatorname{diag}\left(\omega_{1}^{2}, \ldots, \omega_{m}^{2}\right)$ and $m=1+N+G$ denotes the dimension of $\boldsymbol{\theta}_{\boldsymbol{t}}$. The random walk assumption helps focus on permanent shifts and reduces the number of parameters in the estimation procedure.

In sum, substituting (3) into (2):

$$
\mathbf{Y}_{t}=\mathbf{Z}_{t} \boldsymbol{\theta}_{\boldsymbol{t}}+\mathbf{u}_{t}
$$

where $\mathbf{Z}_{t}=\mathbf{X}_{t} \Xi, \Xi=\left[\Xi_{1}, \Xi_{2}, \Xi_{3}\right]$. By combining the data with the above factors, the decomposition in (6) allows us to measure the relative importance of common, State and variable specific influences in explaining fluctuations in $\mathbf{Y}_{t}$. More precisely, $\mathbf{X}_{t} \Xi_{1} \theta_{1 t}$ represents a common indicator for $\mathbf{Y}_{t}$, which can be interpreted as a proxy for the Australian or nationwide business cycle, $\mathbf{X}_{t} \Xi_{2} \theta_{2 t}$ represents the vector of State specific indicators and it can be interpreted as a proxy for each individual State's business cycle, and $\mathbf{X}_{t} \Xi_{3} \theta_{3 t}$ represents a vector of variable specific indicators which can be interpreted as a common cyclical indicator that captures common fluctuations for each endogenous variable across all States. Note that, while the factors are mutually independent, the data enters into each of the indicators, making them correlated by construction. But as the number of States and variables becomes large, the correlation will tend towards zero (Canova et al., 2007). I illustrate a simple example of the model in the online appendix.

\subsection{Comparison with other similar Models}

In this section I contrast the above Panel BVAR model with two similar models used in 
the literature: large BVARs and Dynamic Factor Models (DFMs). ${ }^{5}$ First, large BVAR models of the spirit in Banbura et al. (2010), do not take into consideration the existence of the panel dimension of the data. In other words, all variables are treated symmetrically, regardless of whether they belong to a specific unit/group. Moreover, the types of shrinkage priors normally applied when estimating such models fail to recognise the cross sectional information present within the data-as the coefficients of lagged interdependencies are shrunk towards zero. Second, similar to the large BVAR, the presence of the cross-sectional information is also ignored within DFMs. By this I mean that the dynamic interdependencies are not modelled within the DFM but are instead captured within a set of unobserved factors. Moreover, these unobserved factors are typically derived using averages of (subsets of) the current values of endogenous variables. In contrast, the regressors in (6) are combinations of the lags of the right hand side variables of endogenous variables and thus are observable. Finally, the estimated factors in a DFM reflect the relative variability of the variables used to construct them. This implies that one-to-one comparison of factor cycles cannot be made since the cycles derived from factors are all measured in different units, not a common unit. In contrast, the Panel BVAR construction provides an equal weight on information attached to the subset of the endogenous variables within the model, that is all the variables are measured in the same units (all variables will be demeaned and standardised). Taking these considerations into account, the analysis of business cycles across States or countries is more appropriate within the Panel BVAR framework as it recognises the cross sectional information present in the data which the large BVARs and DFMs ignores.

\subsection{Common Stochastic Volatility}

In the model described above, Canova et al. (2007) assume a time-invariant variancecovariance matrix. I extend this model by allowing for a common stochastic volatility factor process within the error structure of the model (Carriero et al., 2016). Thus, our model

${ }^{5}$ For a more detailed comparison with alternative VAR type models, I refer the reader to the excellent survey by Canova and Ciccarelli (2013). 
includes (6) with:

$$
\begin{gathered}
\mathbf{u}_{t} \sim N\left(0, e^{h_{t}} \Sigma_{u}\right), \\
h_{t}=\mu_{h}+\rho h_{t-1}+\zeta_{t}, \quad \zeta_{t} \sim N\left(0, \sigma_{h}^{2}\right),
\end{gathered}
$$

where $|\rho|<1$. The state equation of (8) follows Carriero et al. (2016) and Mumtaz and Theodoridis (2017) where they employ a common stochastic volatility factor in their model specification. Carriero et al. (2016) commented that this common stochastic volatility factor structure is ideal for models with a large data set. From their results, Carriero et al. (2016) found that large BVAR models with a common stochastic volatility factor error structure significantly improves model fit and forecast accuracy, when compared to a standard conventional large BVAR. The adoption of a common stochastic volatility factor is very important since there have been many studies undertaken in the literature that have documented the importance of stochastic volatility in improving model fit and forecastability (for instance see Clark (2014), Clark and Ravazzolo (2015), and Chan and Eisenstat (2018)). The inclusion of this time-varying volatility error specification allows us to capture any common structural shifts or breaks which are commonly found in the majority of macroeconomic data.

For comparison, I also consider a time-varying parameter Panel BVAR model where the covariance matrix follows a regime switching process, $\mathbf{u}_{t} \sim N\left(0, \Sigma_{j}\right)$ for $j=1, \ldots r$ regimes (Sims and Zha, 2006). I assume the regime indicator $S_{t} \in\{1, \ldots, r\}$ at time $t$ follows a Markov process with the transition probability $\mathbb{P}\left(S_{t}=j \mid S_{t-1}=i\right)=p_{i j}$. As discussed below, I find that the Panel BVAR model with a common stochastic volatility factor has a better in-sample fit compared to a model with regime switching in the covariance terms. 


\subsection{Data}

In our study, I employed four business cycles variables commonly used within the literature, which are: consumption, employment, retail turnover and investment. For instance, in the study by Canova et al. (2007) they use real GDP, industrial production, retail turnover and employment. However, data on real GDP and industrial production are not available across Australian States. Since real GDP and industrial production are proxy for economic activity, the only available data that closely resembles movements in these variables are consumption and investment. The data frequency is quarterly, and the sample period covers dates between 1988Q4 to 2015Q1. Due to the relatively small sample period, and the risk of over-parameterisation, I only impose one lag length on the model ${ }^{6}$. All data variables were gathered from the Australian Bureau of Statistics (ABS). Consumption is final household consumption expenditure and investment is private gross fixed capital formation. Following Ciccarelli et al. (2016), all the data are deseasonalised and deflated first. Then the data are convert to annualised growth rates and finally standardised.

\subsection{Priors}

To calculate the posterior distribution for the model's parameters I implement the prior distributions of:

$$
\begin{gathered}
\Sigma_{u} \sim I W\left(z_{1}, Q_{1}\right), \\
\sigma_{h}^{2} \sim I G\left(w_{1}, S_{1}\right), \\
\omega_{i}^{2} \sim I G\left(w_{0}, S_{0}\right), \quad i=1, \ldots, m ., \\
\mu_{h} \sim N\left(\mu_{0}, V_{\mu_{h}}\right),
\end{gathered}
$$

${ }^{6}$ I plot the sample autocorrelation of the residuals for each variable in the online appendix and I find that majority of the residuals autocorrelation falls within the $95 \%$ confidence bands around zero. Also, I plot the residuals against their fitted values for each variable in the online appendix and I found that all the residuals exhibit a random behaviour. 


$$
\rho \sim N\left(\mu, V_{\rho}\right) 1(|\rho|<1)
$$

where 1(.) denotes an indicator function and I initialised

$$
\theta_{1} \sim N\left(\theta_{0}, \mathbf{V}_{\theta}\right), \quad h_{1} \sim N\left(h_{0}, \frac{\sigma_{h}^{2}}{\left(1-\rho^{2}\right)}\right)
$$

Note that I impose the stationarity condition $|\rho|<1$ through the prior distribution of $\rho$. In practice hyperparameters are either obtained from the data to tune the prior to the specific application, selected a-priori to produce relatively loose priors or initialised with a training sample. Since our sample period is relatively short, there is no training sample available to tune the priors. Therefore, I impose $z_{1}=N G+5, Q_{1}=5 \mathbf{I}_{N G}, \theta_{0}=\mathbf{0}, \mathbf{V}_{\theta}=10 \mathbf{I}_{N G}$, $\mu_{0}=\mu=0, h_{0}=0, V_{\rho}=1, V_{\mu_{h}}=5, w_{0}=w_{1}=5, S_{0}=(.01)^{2} \times\left(w_{0}-1\right)$ and $S_{1}=.01$. These priors are relatively non-informative and standard within the time-varying parameter literature. As mentioned above, Canova and Ciccarelli (2013) note that in Panel BVAR framework, a shrinkage prior is not recommended as it would entail a failure to recognise the cross sectional information present within the data.

\subsection{Estimation}

The time-varying parameter Panel BVAR with a common stochastic volatility factor is es-

timated through a standard Markov Chain Monte Carlo (MCMC) method. Canova and Ciccarelli (2009) follow a standard Kalman filtering and smoothing techniques from Chib and Greenberg (1995) to estimate the model's parameters. Here I adopt a different estimation technique, instead utilizing the precision sampler methods developed in Chan and Jeliazkov (2009) and Chan and Hsiao (2014) to estimate the model's parameters and the common stochastic volatility factor respectively. The main reason I adopt this precision sampler technique is due to its computation efficiency advantage over the Kalman filtering and smoothing techniques. I stored 35,000 draws after the initial 15,000 draws were dis- 
carded. Further details on the Gibbs Sampler can be found in the online appendix. An important issue when using a Gibbs Sampler is the convergence of the limiting distribution of the sample to the posterior distribution. In theory, as the number of draws reaches infinity, the sampler should converge. However, in any applied work, determining how many draws that it will take to make the sample converge is very difficult. To assess whether our sample has converged, I compute a convergence diagnostic from Geweke (1992). A Geweke (1992) convergence diagnostic is calculated by taking the difference between the means $\bar{g}_{a}=\frac{1}{n_{a}} \sum_{i=1}^{n_{a}} \theta^{(i)}$, based on the first $n_{a}$ draws and $\bar{g}_{b}=\frac{1}{n_{b}} \sum_{i=1}^{n_{b}} \theta^{(i)}$, based on the last $n_{b}$ draws and dividing by the asymptotic standard errors of the difference $\sqrt{\frac{\sigma_{n_{a}}^{2}}{n_{a}}+\frac{\sigma_{n_{b}}^{2}}{n_{b}}}$.

Geweke (1992) suggests that $n_{a}$ and $n_{b}$ should be the first 10 percent and last 50 percent of the total draws respectively. Thus, in terms of our estimation, $n_{a}$ is the first 2,000 draws and $n_{b}$ is the last 10,000 draws. If the sequence of the MCMC sampling is stationary, then by the central limit theorem, the distribution of this diagnostic converges to a standard normal. Table 1 shows the posterior means, standard deviations and the convergence diagnostics for selected parameter estimates. Notice that for all the parameter estimates, the convergence diagnostics are all less than the 5 per cent significance level. This implies that the null hypothesis of the convergence to the posterior distribution is not rejected. I also report the trace plots of these selected parameters in the online appendix. For each parameter the chain appears to be stable. Therefore, both the Geweke convergence diagnostics and trace plots indicate that the parameters and state variables are efficiently drawn from the posterior distributions.

Table 1: Geweke Convergence Diagnostics Statistic

\begin{tabular}{|c|c|c|c|c|c|}
\hline Parameter & Mean $\left(n_{a}\right)$ & Stdev. $\left(n_{a}\right)$ & Mean $\left(n_{b}\right)$ & Stdev. $\left(n_{b}\right)$ & CD \\
\hline \hline$\theta_{10}$ & 0.188 & 0.005 & 0.183 & 0.002 & 1.000 \\
\hline$\theta_{550}$ & 0.115 & 0.004 & 0.109 & 0.002 & 1.019 \\
\hline$\theta_{1600}$ & -0.132 & 0.003 & -0.130 & 0.001 & -1.036 \\
\hline$\omega_{3}^{2}$ & 0.002 & 0.000 & 0.002 & 0.000 & 0.995 \\
\hline$\omega_{7}^{2}$ & 0.001 & 0.000 & 0.001 & 0.000 & 1.085 \\
\hline$\left(\Sigma_{u}\right)_{20}$ & -0.021 & 0.001 & -0.020 & 0.000 & -1.070 \\
\hline$h_{60}$ & 1.294 & 0.002 & 1.297 & 0.001 & 0.996 \\
\hline
\end{tabular}




\section{Empirical Results}

I estimated three components or indices of the econometric model: a common indicator that is a proxy for the Australian business cycle, one State-specific indicator for each Australian State business cycle and four variable specific cyclical common indices. For the first subsection, I undertake a model comparison exercise. In the second sub-section, I examined the common factor stochastic volatility across all the variables. For the third sub-section, I determined whether there was significant common movement in the four variables across each Australian State. In regards to the fourth sub-section, I assessed the synchronicity of each Australian State-specific indicator. For the last sub-section, I tried to determine the relative weight of each of the four variable type indices in explaining the GFC across each Australian State.

\subsection{Model Comparison}

To determine whether the proposed new methodological feature of the model is favoured by the data, I undertake a model comparison exercise in which I compare the time-varying parameter Panel BVAR with a common stochastic volatility factor (TVP-PVAR-CSV) against the time-varying parameter Panel BVAR with a constant variance (TVP-PVAR). I also compare the benchmark model against the time-varying parameter Panel BVAR model with regime switching in the covariance matrix and I consider two (TVP-PVAR-RS1), three (TVPPVAR-RS2) and four (TVP-PVAR-RS3) regimes. To this end, the marginal likelihood for

each of the models is computed as the product of the one-step-ahead predictive likelihood of Geweke and Amisano (2011). The reason for using the one-step-ahead predictive likelihood as compared to the harmonic mean estimator as in Canova and Ciccarelli (2012) is that recent work has shown that this approach can be extremely inaccurate. More precisely, Chan and Grant (2015) show that the 14 marginal likelihood estimates computed using the (modified) harmonic mean as in Gelfand and Dey (1994) can have a substantial finite sample bias and can thus lead to inaccurate model selection. 
Following Geweke and Amisano (2011) the marginal likelihood for the $i-t h$ model is:

$$
p\left(\mathbf{Y} \mid M_{i}\right)=p\left(\mathbf{Y}_{1} \mid M_{i}\right) \prod_{t=1}^{T-1} p\left(\mathbf{Y}_{t+1} \mid \mathbf{Y}_{t}, \ldots \mathbf{Y}_{1}, M_{i}\right)
$$

where $p\left(\mathbf{Y}_{t+1} \mid \mathbf{Y}_{t}, \ldots \mathbf{Y}_{1}, M_{i}\right)$ is the one-step-ahead predictive likelihood given the data up to time $t$ under model $M_{i}$. This marginal likelihood computation has been employed in numerous empirical applications, for instance see Chan and Eisenstat (2018) and Chan et al. (2018). The marginal likelihood results are reported in Table 2. The results clearly show that the TVP-PVAR-CSV is the best model out of the five considered. This means that the addition of the common stochastic volatility factor in the econometric methodology is a key feature of Australian State level data. In terms of the comparison between the common stochastic volatility factor and the regime switching covariances, my findings are similar to Chan and Eisenstat (2018) where the data supports model's with a volatility process instead of model's with discrete breaks in the covariance terms.

Table 2: Log marginal likelihood estimates for selected models

\begin{tabular}{|c|c|c|c|c|c|}
\hline & TVP-PVAR & TVP-PVAR-CSV & TVP-PVAR-RS1 & TVP-PVAR-RS2 & TVP-PVAR-RS3 \\
\hline \hline Log-ML & -5942.6 & $\mathbf{- 5 1 3 2 . 1}$ & -6308.10 & -6401.8 & -6423.0 \\
\hline
\end{tabular}

\subsection{Common Stochastic Volatility}

Figure 1 plots the posterior median of the common stochastic volatility factor, expressed as a standard deviation, from the model. It is clear that there is significant time variation within the common stochastic volatility factor. In general, the common stochastic volatility factor trend appears to be declining over time. This declining trend implies that the Australian business cycle is less susceptible to large fluctuations or shocks over time. However, the common volatility does exhibit a significant increase during the late 1990s to early 2000s. This sharp increase in common volatility could be attributed either to the introduction of the Goods and Services Tax, or international factors, mostly likely the Asian Financial Crisis of 1997-98. Also, there appears to be no pronounced jump in volatility during the recent Global Financial Crisis, which suggests that the Global Financial Crisis had less of an impact on 
the Australian economy. This result is plausible since, technically, the Australian economy did not experience a recession during this crisis period. Another issue is that Australia has a close proximity to Asia and most of Australia's major trading partners are from this region. Therefore, the Australian economy will be highly influenced by the economic performances of countries in this region compared to the US economy. These two episodes highlights the importance of stochastic volatility in the error structure since each crisis (or shocks) have differing impacts on the economy.

To see whether this result is robust, I also plotted the posterior median estimates of the stochastic volatility variable for each of the aggregated variables from an univariate one lag autoregressive model with stochastic volatility (AR-SV(1)) in Figure 2. The stochastic volatility for total consumption growth has the same declining trend as in the common stochastic volatility factor in Figure 1. However, for total employment, investment and retail turnover growths, the stochastic volatility for all these variables only exhibits a declining trend after 2000. Notice that the stochastic volatility for both investment and retail growths peaked around the late 1990s and early 2000s. This could provide explanation towards the sharp increase in the common stochastic volatility factor at the same time. Therefore, the common stochastic volatility factor appears to capture the declining volatility trend in all these four variables.

\subsection{Commonality}

Figure 3 shows the evolution of the common indicator for all series, expressed as the standard deviations from the historical average annual growth rates. The common indicator is very volatile and the majority of the 68 per cent posterior credible interval consistently includes zero over time. This implies there is a large degree of parameter uncertainty associated with the common indicator. However, the common indicator does appears to capture the early 1990's recession and the recent slowdown that the Australian economy experienced due to the GFC. To measure the contribution of the common indicator on each State, I follow Canova and Ciccarelli (2012) and compute a simple numerical measure that explains how much of 
Table 3: Percentage of variance explained by the common indicator

\begin{tabular}{|c|c|}
\hline & Common \\
\hline \hline NSW & $26.60 \%$ \\
\hline VIC & $11.21 \%$ \\
\hline QLD & $20.31 \%$ \\
\hline SA & $45.75 \%$ \\
\hline WA & $19.27 \%$ \\
\hline TAS & $21.90 \%$ \\
\hline NT & $83.78 \%$ \\
\hline ACT & $86.81 \%$ \\
\hline Average & $39.45 \%$ \\
\hline
\end{tabular}

the variance of each of the State indicator is explained by the common indicator. Table 3 shows the results of this measure for each Australian State. I find on average the common indicator explains about 39 per cent of the fluctuations across each of the State indicators. For comparison, the study by Canova et al. (2007) found that the common indicator explains about 30 per cent fluctuations across each of the G7 countries. The common indicator appears to have the largest influence in SA, NT and ACT business cycles or State-specific indicators compared to the other Australian States. Note that, from Table 3, if I exclude both ACT and NT from the calculation, I find that, on average, the common indicator explains only about 24 per cent of the fluctuations across each of the State indicators.

Although there is a large degree of parameter uncertainty associated with common indicator, the results from Table 3 appear to indicate that the common indicator does have significant influence across each State's business cycle. To further investigate whether the common indicator is robust, in Figure 4 I plot the posterior median of the common indicator together with the OECD CLIs for Australia. The OECD CLIs are indices that measure fluctuations of economic activity or business cycles of a particular country. Figure 4 shows that the model's common indicator captures majority of the upturn and downturn displayed in the OECD CLI. It appears that since 2000, the common indicator trend or fluctuations closely resemble the trend line of the OECD CLI. In addition, our common indicator captures the recent slowdown due to the GFC earlier than the OECD CLI. Therefore, based on the visual comparison with the OECD CLI, it appears that the common indicator captures 
the majority of the fluctuations in economic activity present during this sample period.

Figure 5 shows the variable specific indices for all the Australian States. As mentioned above, each variable specific indicators can be interpreted as a common cyclical indicator that captures common fluctuations for each endogenous variable across all the States. Apart from the employment indicator, the majority of the other variables specific indices 68 per cent posterior credible interval includes zero for most dates. Similarly, this implies that consumption, retail turnover and investment variable components/indices exhibit a large degree of parameter uncertainty. This means that each of these three variables do not feature a significant common movement across the States. However, the consumption indicator does appear to be statistically significant from 2006 onward, as the 68 per cent posterior credible interval lies above and below zero. Furthermore, I find that the common indicator explains about 25, 8, 9 and 111 per cent of fluctuations in consumption, employment, retail turnover and investment indices respectively. This result is consistent with theory since both consumption and investment contribute to a large portion of output, and I would expect these two variables to be the main driver of fluctuations across the State's business cycle.

The early 1990s' recession appeared to have a significant negative impact on employment growth across the States. Both consumption and investment growth were also affected by this recession, yet their fall was considerably less than that of employment growth. However, irrespective of the aforementioned, this recession only had a minimal impact on total State retail turnover growth. The introduction of the Goods and Services Tax during the early 2000s appears to have only a negative impact on retail turnover growth. For the period before the GFC, the posterior median for both consumption and employment growths were significantly positive which implies that the Australian economy was in a period of successful growth before the GFC hit. The GFC had an immediate, negative impact on consumption, employment and retail turnover growth across all the States. Investment growth appeared to be unaffected by this crisis. Employment and consumption growth were the worst affected by this crisis in comparison to the two other variables. Both consumption and employment growth during 2013 to 2015 have remained sluggish and they have not recovered back to 
pre-GFC levels. In comparison, retail turnover growth became close to positive around late 2014 or early 2015. Therefore, from variable-specific indices, the fall in consumption and employment growths, across all the States, can be attributed to the slowdown that the Australian economy experienced during the GFC.

\subsection{Convergence or Divergence}

To assess the similarities and synchronicity of each Australian State business cycles, I plot each Australian State-specific indicator or component in Figure 6. It is clear that the majority of the State's 68 per cent posterior credible interval includes zero for most dates. This implies that their explanatory power for domestic fluctuations over the sample period is small. For example, excluding TAS, during the period between the early 2000s to the mid 2000s, cyclical fluctuations across the States were very minor. However, upon visual examination of Figure 6, each State's cyclical fluctuations differ in intensity, timing and duration. For instance, cyclical fluctuations in QLD and TAS are relatively more persistent compared to the other States. The early 1990's recession had a negative effect on the majority of States. It appears that the both VIC and WA economies were the worst affected by this recession, in comparison to other States. In regards to the GFC, the QLD economy was the worst affected out of all the States; the QLD State indicator has been falling since 2008. Both the WA and TAS economies were also affected by this crisis, and similarly their recovery appears to also be sluggish. The GFC seemed to have a minimal impact on both the NSW and VIC economies. However, the NSW economy appears to experience a downturn during late 2014, or early 2015. For the Territories, cyclical fluctuations are very weak across both the ACT and NT economies. Based on these descriptive findings, each State's cycles has unique a pattern, and there appear to be no common similarities amongst the States.

To further assess the synchronicity of each Australian State's business cycles, I followed a similar strategy to Canova and Ciccarelli (2012) and plot in Figure 7 the pairwise rolling correlations between each State indicator. The rolling correlations are computed using 10 
years of data ending at the date listed on the horizontal axis. Due to our small sample size, I was only able to compute the rolling pairwise correlations for the 2000's period. According to Canova and Ciccarelli (2012), if convergence (divergence) takes place I should see these correlations uniformly increase (decrease) with time.

The correlations display distinct periods of convergence and divergence across the States. Firstly, focusing on mining States, the correlation between QLD and WA has remained surprisingly low during the period of 2002 to 2009 when the mining boom was most prevalent. Apart from the periods around 2010, SA is the only non-mining State that has a consistently high correlation with QLD over the 2000s. WA mainly has a consistently negative correlation with all the other States, except for TAS and ACT. For the two largest State economies, NSW and VIC, their correlation with each other has also persistently remained negative over the 2000s. This is also the case for the Territories, where they appear to be less correlated with major Australian States. Figure 8 reports the average correlations between a State indicator with all the others States for the periods of the 1990s and 2000s. It appears that only WA and ACT have increased their degree of synchronisation with other States between the 1990s to 2000s. Overall, Figure 8 shows that the degree of synchronisation on average across the States, in terms of correlation, has decreased by about half from the 1990s to 2000s. In other words, State economic performance or cyclical fluctuation has clearly diverged during the 2000s period.

The above findings undercover four facts. Firstly, the mining boom in QLD and WA were not synchronised; each of their booms were driven by idiosyncratic factors. An explanation for this non-synchronisation could be due to the differentiation in their exports of resources and minerals. For example, QLD is a large exporter of coal production, whilst for WA, iron ore dominates the exports. Secondly, the mining boom in QLD had a positive effect on the SA economy. Thirdly, the mining boom of WA had no spillover effects to the other major States economies. Lastly, the economic performances of the Territories (ACT and NT) were less synchronised with the major States. Therefore, these findings show that cyclical fluctuations were clearly different and became less synchronised across each State 
and Territories during the 2000's. Thus, there is evidence of heterogeneity present within each State's business cycle.

\subsection{Historical Decomposition}

To determine the relative weight of each of the four variable type indices in explaining the GFC across each Australian State, I compute the historical decomposition of each State's final demand growth, in Figure 9, for the period between 2005Q3 to 2015Q1. Since the Panel BVAR is a large system, it is very difficult to impose any structural identification on the model, which is noted in Canova and Ciccarelli (2012) and Ciccarelli et al. (2016). Therefore, in this study, I compute the historical decomposition based on the estimation of a State by State factor-augmented VAR for final demand growth, which consists of the aggregation of both investment and consumption (both private and public), and the four variable-specific indices estimated from the TVP-PVAR-CSV model. The four variable-specific indices from our Panel BVAR explicitly captures aggregate fluctuations across each States and the inclusion of these indices into this VAR will allow us to capture the dynamic interdependencies between each State's individual fluctuations and the fluctuations across the rest of Australia. For the identification of the State VAR, I follow a standard recursive assumption and order the investment indicator first, followed by consumption, sales, employment indices and the State's final demand growth last. For robustness, I changed the ordering of these variables and the results were very similar.

Figure 9 show that the majority of States were hit by the GFC during late 2008 and early 2009. Falling consumption growth appears to be the dominant factor in driving the crisis in the TAS, VIC and QLD economies. This fall also had negative impacts on the NSW (see Table 2: Percentage of variance explained by the common indicator), ACT and WA economies, however, the impact or contribution is relatively small compared to the three aforementioned States. It should be noted, that this crisis can also be explained by a fall in employment growth in VIC, QLD and ACT economies. For the SA and NT economies, State-related idiosyncratic factors were also a dominant feature in driving the crisis. Turning 
to the period of 2013 to 2015, it is clear that the majority of States have not recovered from the GFC. For instance, falling consumption growth again appears to be contributing to the downturn in both the QLD and TAS economies. Apart from the QLD, TAS and NSW economies, all four common variable-specific indices had a minimal contribution on the downturn experienced by the other States. Therefore, the results from the historical decomposition show that the fall in consumption growth was the main factor in driving the negative effects of the GFC across the majority of the States.

\section{Conclusion}

The objective of this study is to assess the synchronicity and nature of Australian State business cycles. To this end, I have proposed a simple extension of the time-varying parameter Panel BVAR in which the error structure is augmented to have an additional common stochastic volatility factor. A model comparison exercise reveals that the addition of the common stochastic volatility factor significantly improved the model's in-sample-fit. This suggests that stochastic volatility is an important feature when modelling the Australian economy. More precisely, the common stochastic volatility factor reveals that the Australian economy exhibited a large jump in volatility during the Asian Financial Crisis of 1997-98, but no such jump was observed during the recent Global Financial Crisis. This result is plausible because the Australian economy technically did not experience a recession during the recent crisis period. One possible explanation for this result is that the Australian economy is highly influenced by the economic performances of countries within the Asian region rather than the US economy and the Asian economies were relatively unaffected by the recent crisis. In any event, the fact that these two crises have such diverse impacts on the economy further highlights the importance of allowing for stochastic volatility in the models error structure.

Our main empirical finding is that, with the exception of economic contractions, there appears to be significant co-movement among the Australian States and Territories. That 
being said, over the past two decades, the degree of synchronisation across Australian States has decreased, on average, by about half. This result is supported by the State's pairwise correlation and historical decomposition of the States' final demand, which indicate strong heterogeneity among the Australian States' business cycles. This implies that national or federal policymakers should monitor, or emphasise, each individual State's economic performance instead of the combined performance of the all States when implementing a macroeconomic policy. Thus, policy measures that are designed based on national interest could be ineffective or even counter-productive to each State's economy. In addition, the results indicate that the federal government should consider allowing each State government to pursue an active role in managing their own economy, since idiosyncratic factors are the main driver of the majority of the States' cyclical fluctuations.

There are several questions that our paper has left unanswered. The pairwise correlations show that synchronicity varies among each State. It would be intriguing to discover an explanation for why some States share a higher correlation whilst others have a lower correlation. Furthermore, it will be interesting to examine the relationship between Australia's major trading partner business cycles and each States business cycle, and whether there is synchronicity and commonality between the States and their trading partners' economic performances. 


\section{$5 \quad$ Figures}

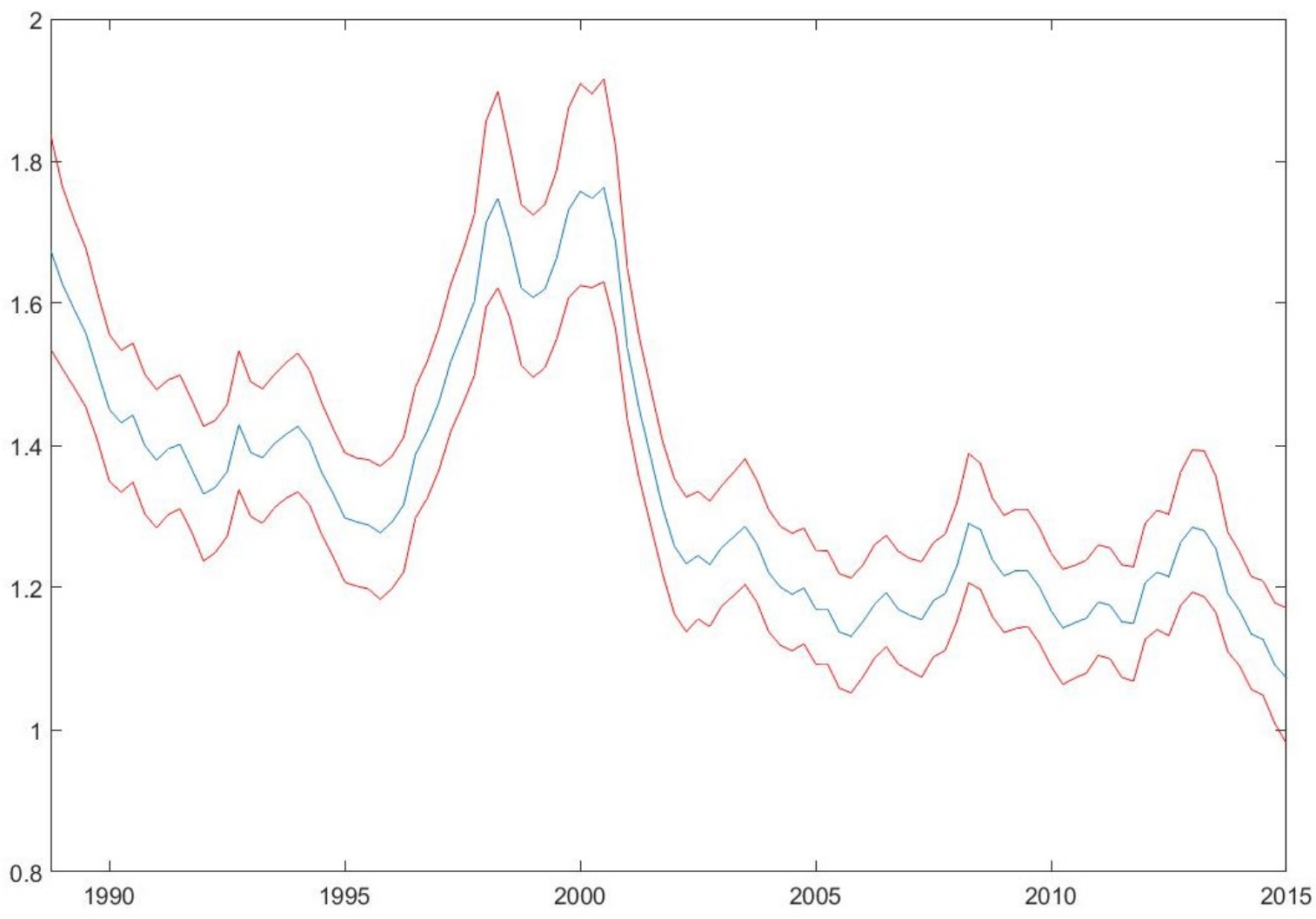

Figure 1: Posterior median (blue line), 16th (red line) and 84th (red line) percentiles of the common factor stochastic volatility (expressed as standard deviation). 

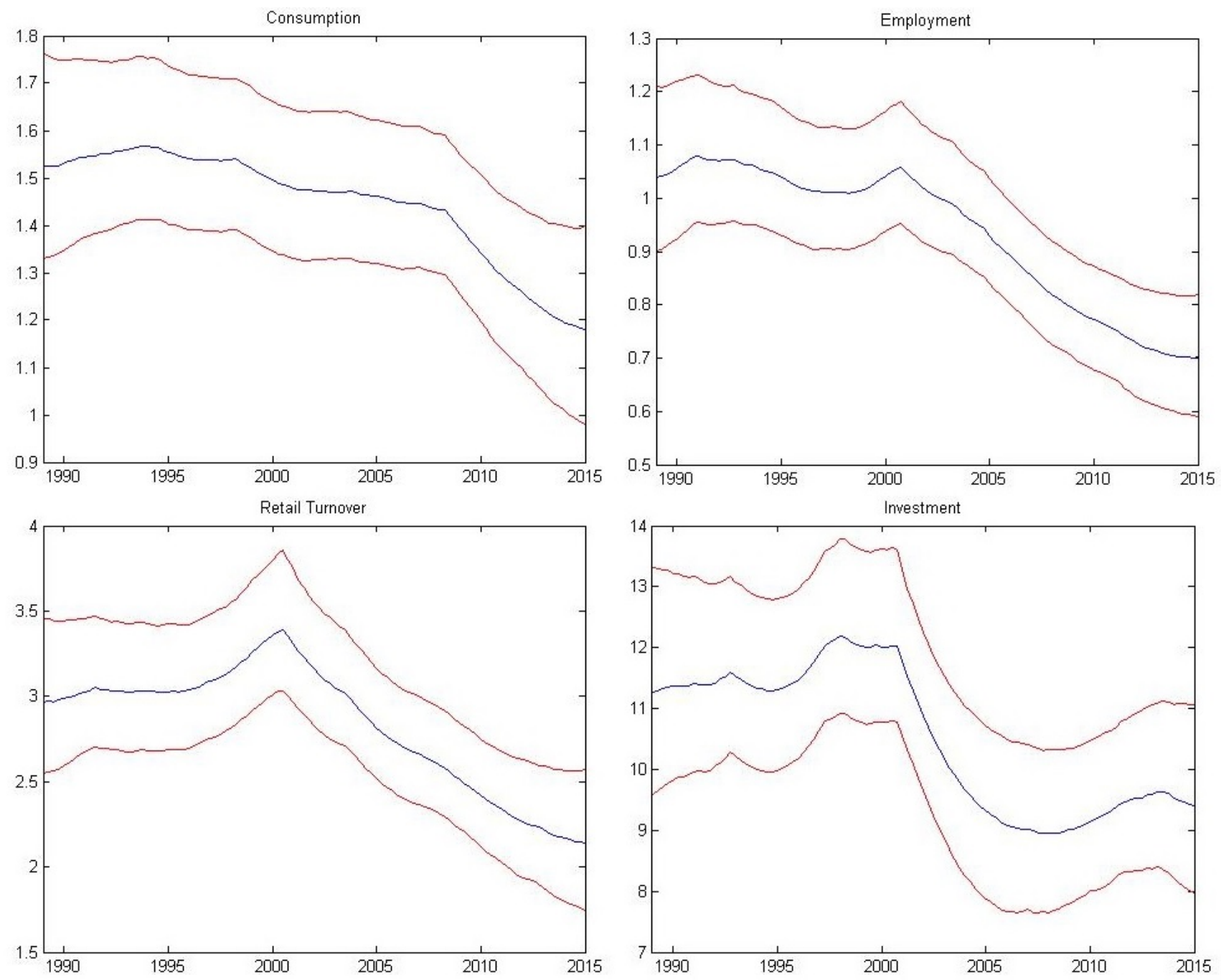

Figure 2: Posterior median (blue line), 16th (red line) and 84th (red line) percentiles of the stochastic volatility (expressed as standard deviation) from AR-SV(1) model. 


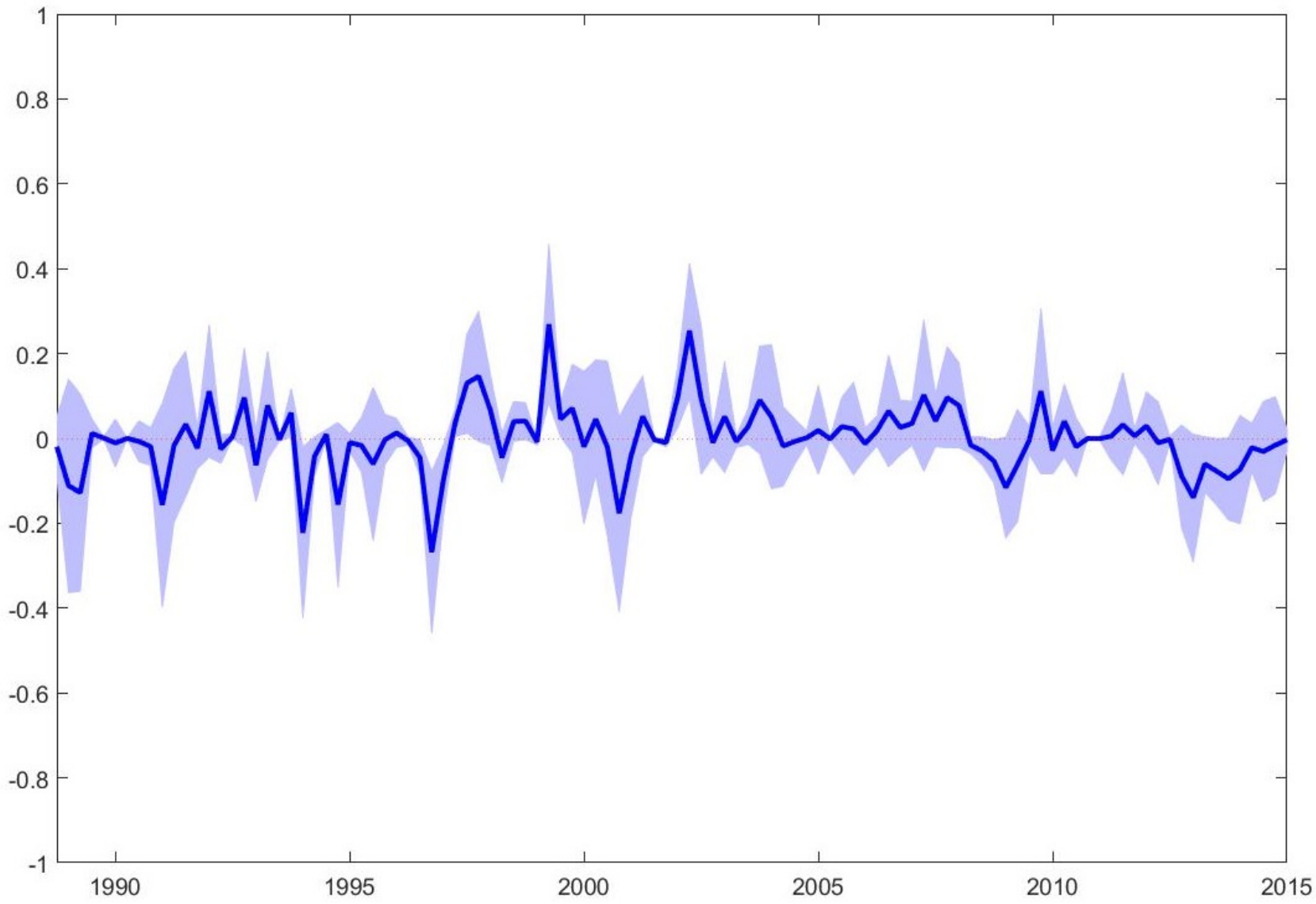

Posterior median (blue line) and 68\% Bayesian credible interval (shaded area)

Figure 3: Plot of common indicator over time 


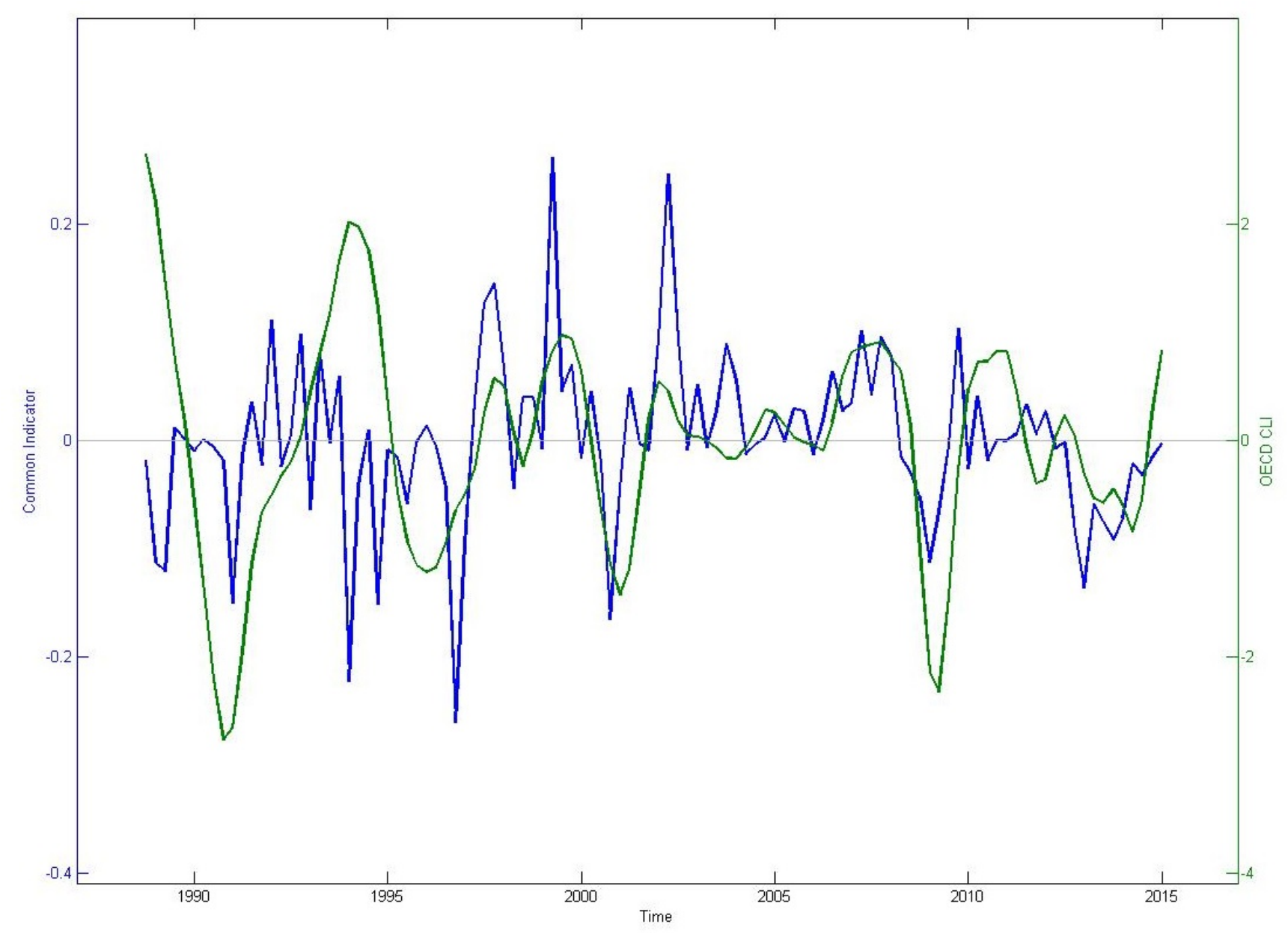

Common indicator (blue line) and OECD composite leading indicator for Australia (green line)

Figure 4: Plot of the posterior median common indicator and the OECD composite leading indicator (CLI) over time 

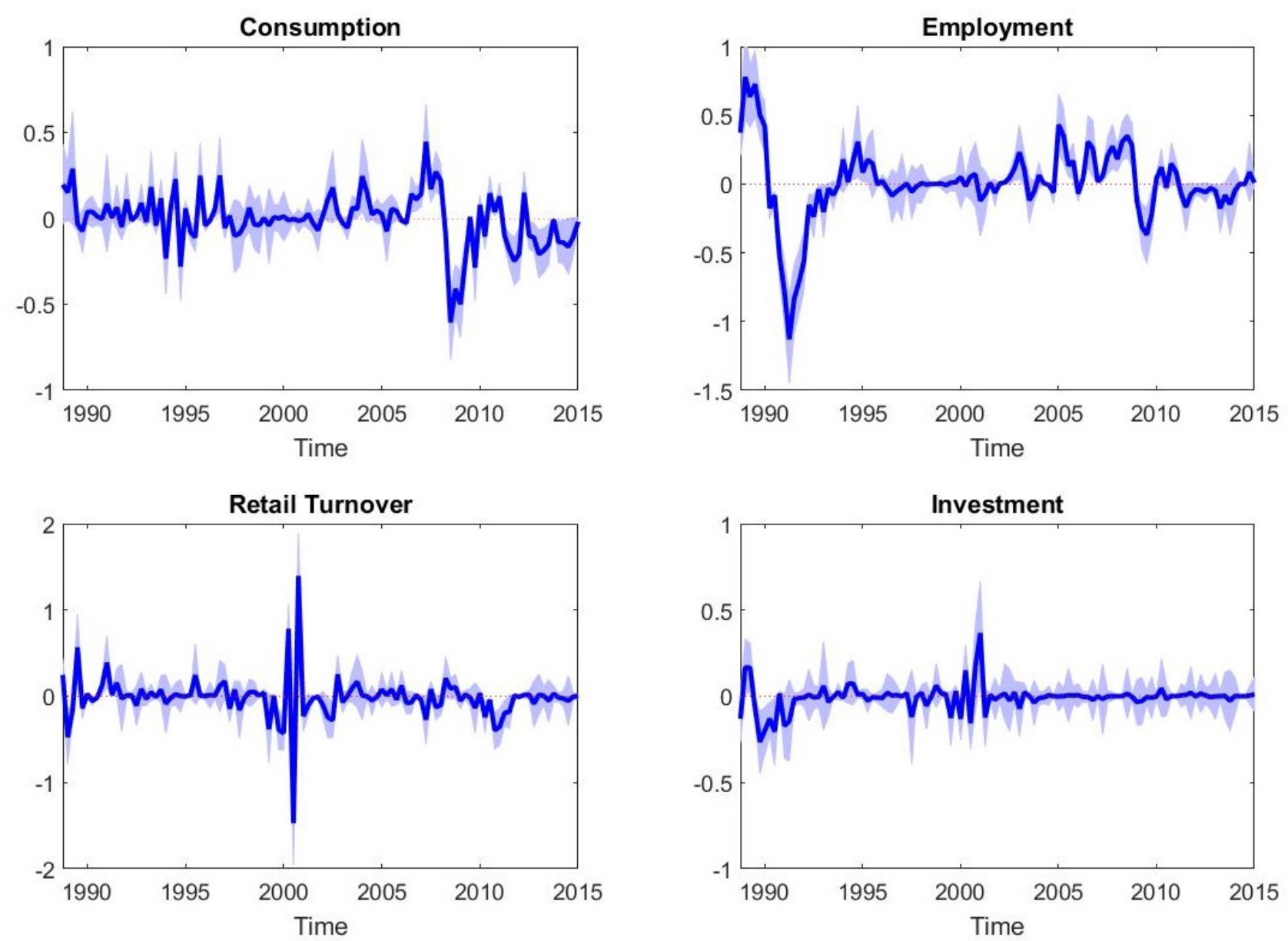

Posterior median (blue line) and 68\% Bayesian credible interval (shaded area)

Figure 5: Plot of variable-specific indices over time 
NSW

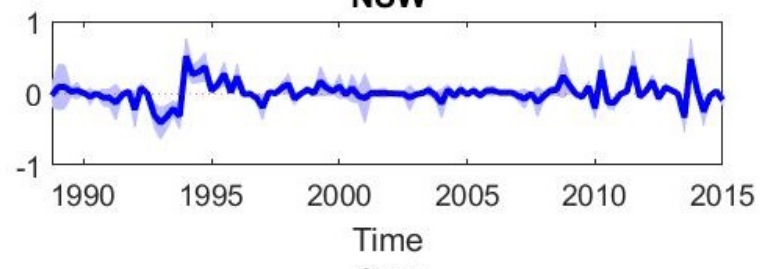

QLD

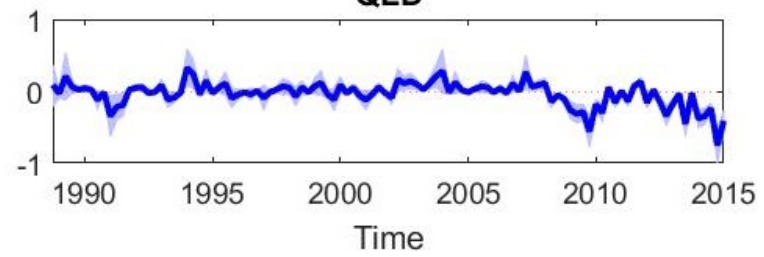

WA

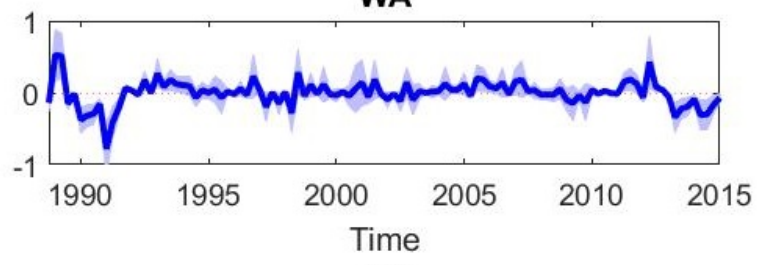

NT

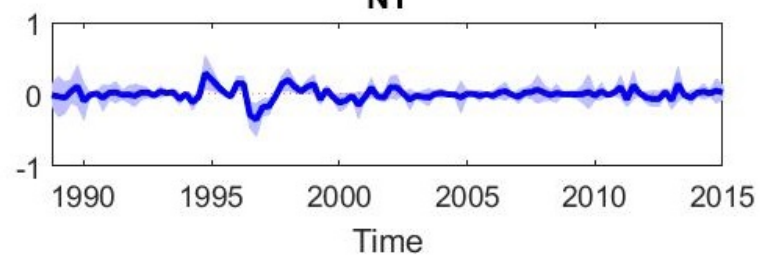

VIC

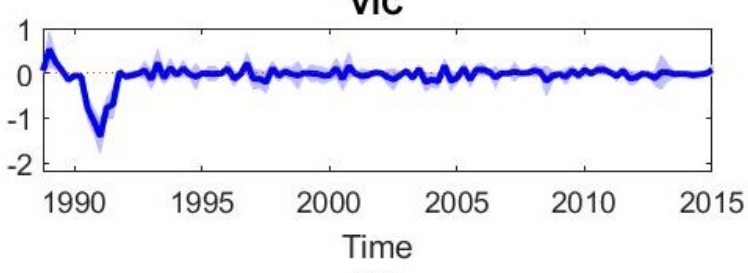

SA

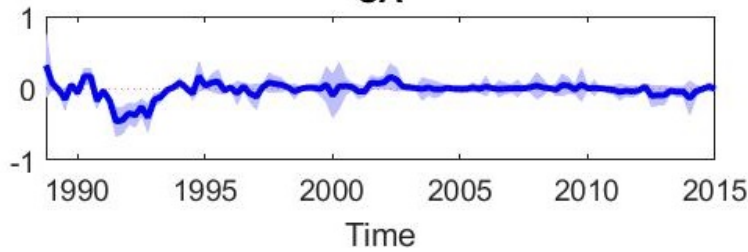

TAS

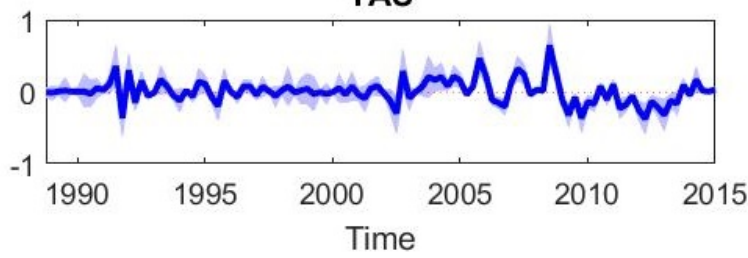

ACT

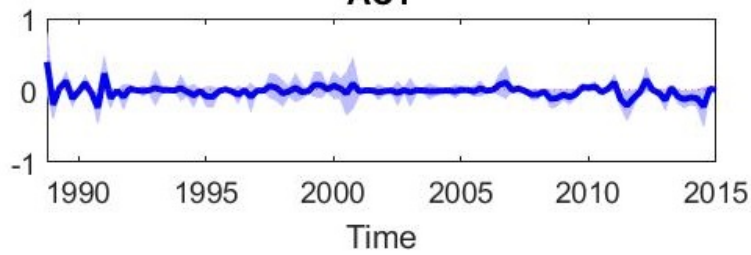

Posterior median (blue line) and 68\% Bayesian credible interval (shaded area)

Figure 6: Plot of State Indices over time 

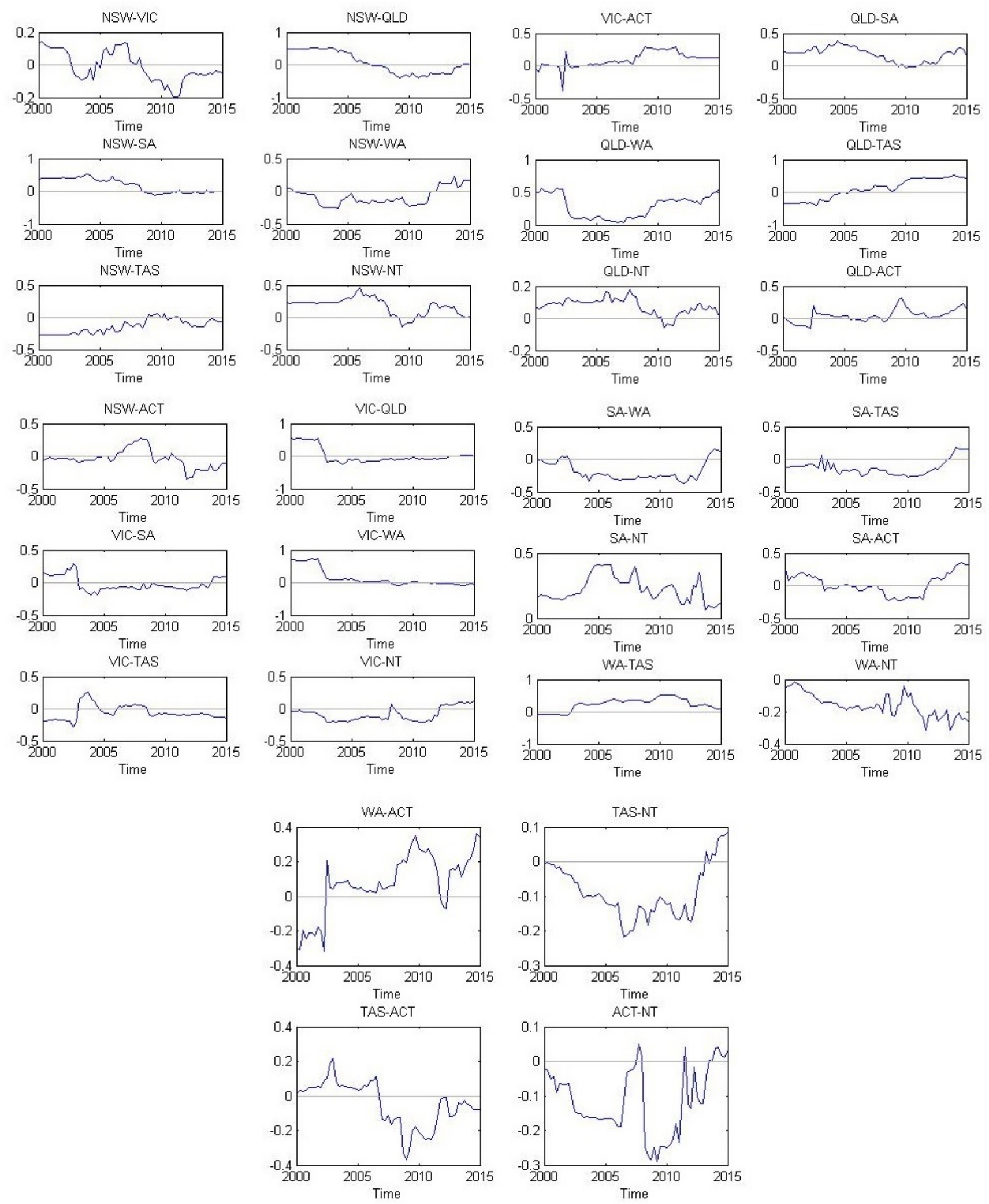

Figure 7: Plot of pairwise rolling correlations between the State factors 


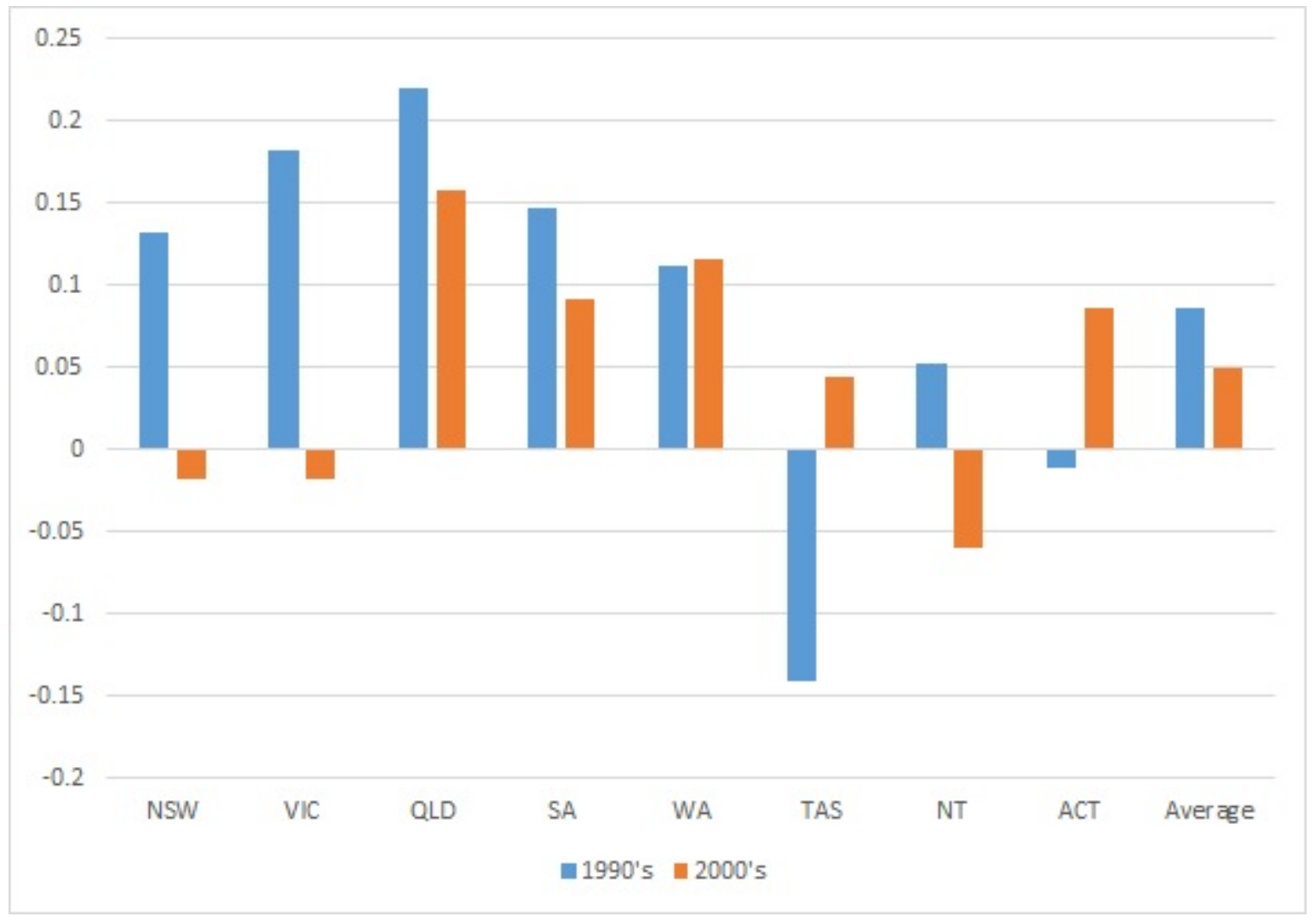

Figure 8: Plot of average correlations between a State indicator with all others 

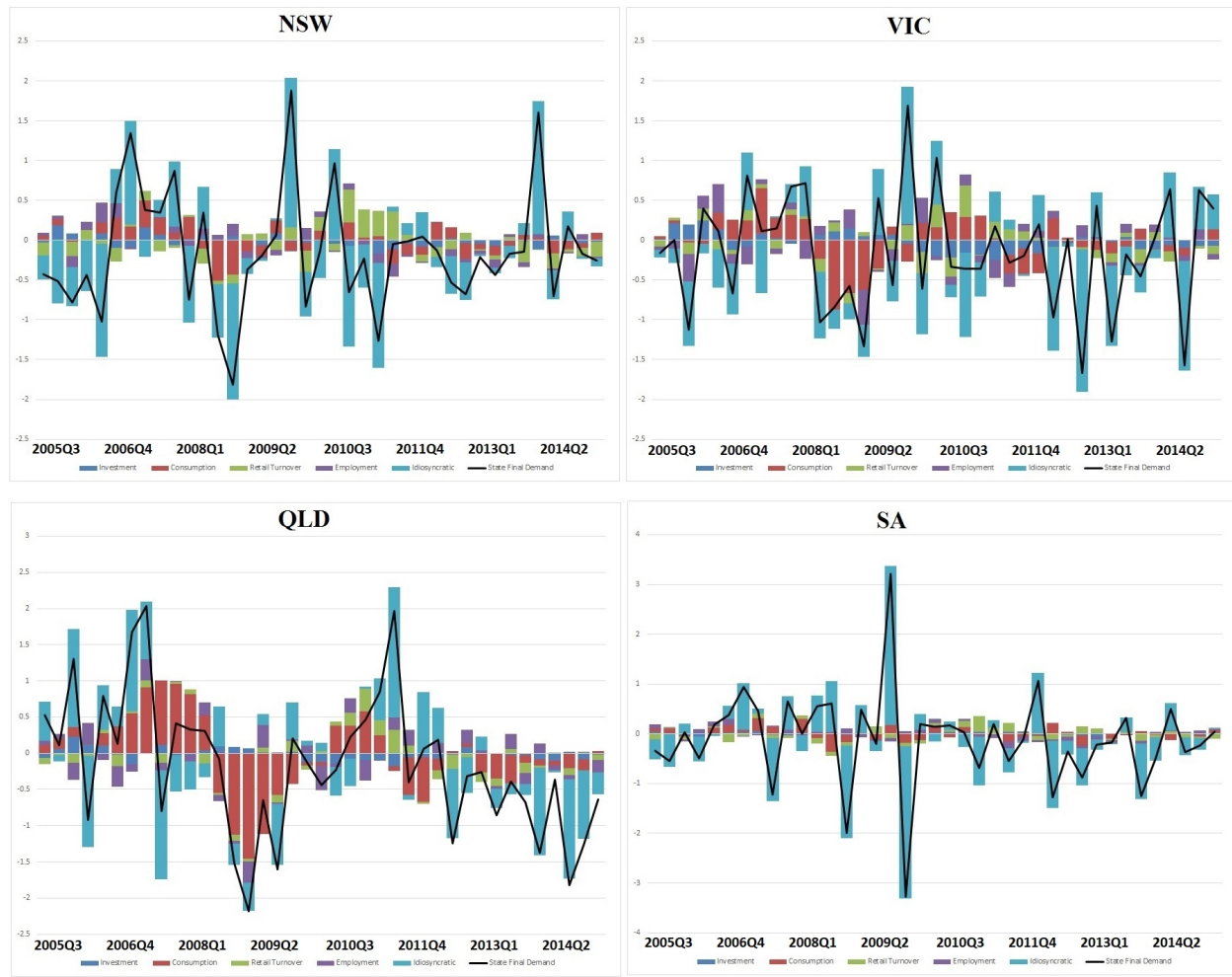

WA

NT
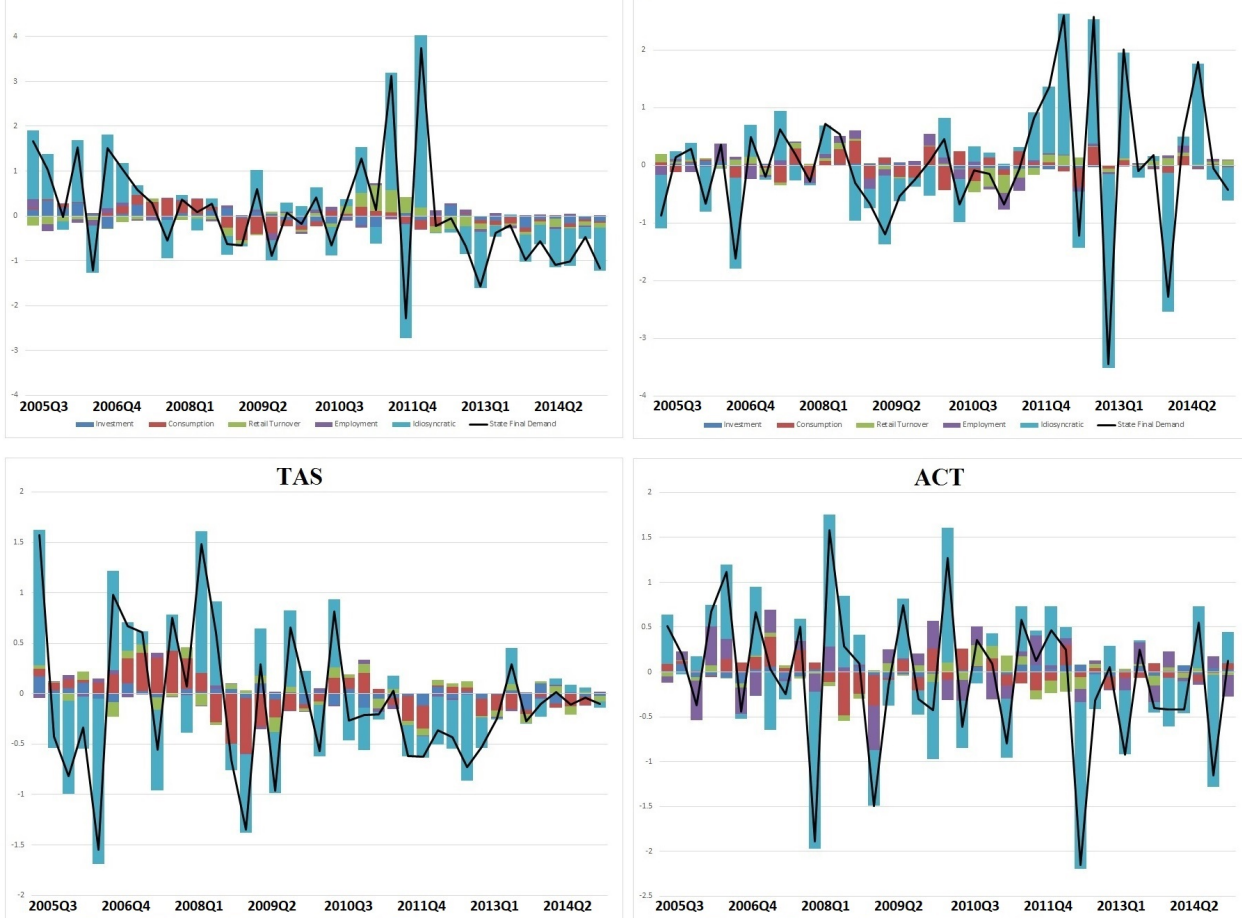

Investment (Dark Blue), Consumption (Red), Retail Turnover (Green), Employment (Purple), Idiosyncratic (Light Blue) and State Final Demand (Black Line)

Figure 9: Plot of Historical Decomposition 


\section{References}

[1] Au-Yueng, W., Keys, A., and Fischer, P. (2012). "Australia-China: Not just 40 years". The Economic Roundup Issue 4, The Australian Treasury. Retrieved from https://treasury.gov.au/publication/economic-roundup-issue-4-2012/australia-chinanot-just-40-years /

[2] Bańbura, M., Giannone, D., and Reichlin, L. (2010). "Large Bayesian vector auto regressions." Journal of Applied Econometrics, vol. 25(1), pp. 71-92.

[3] Battellino, R. (2010). "Twenty Years of Economic Growth." The Reserve Bank of Australia Speeches.

[4] Canova, F, and Ciccarelli, M. (2009). "Estimating Multicountry VAR Models." International Economic Review, vol. 50(3), pp. 929-959.

[5] Canova, F, and Ciccarelli, M. (2012). "ClubMed? Cyclical fluctuations in Mediterranean basin." Journal of International Economics, vol. 88, pp. 162-175.

[6] Canova, F, and Ciccarelli, M. (2013). "Panel Vector Autoregressive Models: A Survey." in Thomas B. Fomby, Lutz Kilian, Anthony Murphy (ed.) VAR Models in Macroeconomics - New Developments and Applications: Essays in Honor of Christopher A. Sims (Advances in Econometrics, Volume 32) Emerald Group Publishing Limited, pp.205 246.

[7] Canova, F, Ciccarelli, M and Ortega, E. (2007). "Similarities and convergence in G-7 cycles." Journal of Monetary Economics, vol 54(3), pp. 850-878.

[8] Carriero, A, Clark, T, and Marcellino, M. (2016). "Common Drifting Volatility in Large Bayesian VARs." Journal of Business and Economics Statistics, vol. 34(3), pp. 375-390.

[9] Chan, J. and Eisenstat, E. (2018). "Bayesian Model Comparison for time-varying parameter VARs with stochastic volatility." Journal of Applied Econometrics. Forthcoming 
[10] Chan, J., and Grant, A,. (2015). " Pitfalls of Estimating the Marginal Likelihood using the Modified Harmonic Mean." Economics Letters, vol. 131, pp. 29-33.

[11] Chan, J. and Hsiao, C. (2014). "Estimation of Stochastic Volatility Models with Heavy Tails and Serial Dependence." In: I. Jeliazkov and X.-S. Yang (Eds.), Bayesian Inference in the Social Sciences, pp. 159-180, John Wiley \& Sons, Hoboken, New Jersey.

[12] Chan, J. and Jeliazkov, I. (2009). "Efficient Simulation and Integrated Likelihood Estimation in State Space Models." International Journal of Mathematical Modelling and Numerical Optimisation, vol. 1, pp. 101-120.

[13] Chan, J. C., Clark, T. E., \& Koop, G. (2018). "A New Model of Inflation, Trend Inflation, and Long-Run Inflation Expectations." Journal of Money, Credit and Banking, vol. 50(1), pp. 5-53.

[14] Chib, S, and Greenberg, E. (1995). "Hierarchical Analysis of SUR Models with Extensions to Correlated Serial Errors and Time-Varying Parameter Models." Journal of Econometrics, vol. 68, pp. 409-31.

[15] Ciccarelli, M, Ortega, E, and Valderrama, M. (2016). "Commonalities and CrossCountry Spillovers in Macroeconomic-Financial Linkages." The BE Journal of Macroeconomics, vol. 16(1), pp. 231-275.

[16] Clark, T.E. (2012). "Real-time density forecasts from Bayesian vector autoregressions with stochastic volatility." Journal of Business 8 Economic Statistics. vol. 29(3), pp. 327-341.

[17] Clark, T.E. and Ravazzolo, F. (2015). "Macroeconomic Forecasting Performance under Alternative Specifications of Time-Varying Volatility." Journal of Applied Econometrics, vol. 30(4), pp. 551-575.

[18] Cross, J., \& Poon, A. (2016). "Forecasting structural change and fat-tailed events in Australian macroeconomic variables." Economic Modelling, 58, 34-51. 
[19] Dixon, R, and Shepherd, D. (2001). "Trends and Cycles in Australian State and Territory Unemployment Rates" The Economic Record, vol.77(238), pp.252-269.

[20] Garton, P. (2008). "The resources boom and the two-speed economy." Economic Roundup Issue 3, The Australian Government Treasury.

[21] Gerard, H., and Kearns, J. (2011). "The Australian Economy in the 2000s." Proceedings of a Conference, The Reserve Bank of Australia.

[22] Geweke, J. (1992), "Evaluating the Accuracy of Sampling-Based Approaches to the Calculation of Posterior Moments." In Bayesian Statistics 4 (eds. J.M. Bernardo, J. Berger, A.P. Dawid and A.F.M. Smith), Oxford: Oxford University Press, pp. 169-193.

[23] Geweke, J., and Amisano, G. (2011). "Hierarchical Markov Normal Mixture Models with Applications to Financial Assets Returns." Journal of Applied Econometrics, vol. 26(1), pp. 1-29.

[24] Gelfand, A. E., and Dey, D. K. (1994). "Bayesian model choice: asymptotics and exact calculations." Journal of the Royal Statistical Society. Series B (Methodological), pp. $501-514$.

[25] Mumtaz, H., and Theodoridis, K. (2017). "The changing transmission of uncertainty shocks in the US." Journal of Business and Economic Statistics, pp. 1-14.

[26] Norman, D., and Walker, T. (2007). "Co-Movement of Australian State Business Cycles." Australian Economic Papers, vol. 46(4), pp. 360-374.

[27] Kim, S., Shephard, N, and Chib, S. (1998). "Stochastic Volatility: Likelihood Inference and Comparison with ARCH models." Review of Economic Studies, vol. 65(3), pp. 361393.

[28] Sims, C. A., \& Zha, T. (2006). "Were there regime switches in US monetary policy?." American Economic Review, vol 96(1), pp. 54-81. 